\title{
Effect of a 4-week Nordic walking training on the physical fitness and self- assessment of the quality of health of women of the perimenopausal age
}

\author{
Mariola Saulicz ${ }^{1,2}$, Edward Saulicz ${ }^{2,3}$, Andrzej Myśliwiec ${ }^{3}$, Tomasz Wolny2,3, Paweł Linek ${ }^{3}$, Andrzej Knapik \\ Jerzy Rottermund 5
}

${ }^{1}$ Department of Physiotherapy in Internal Organ Diseases, The Jerzy Kukuczka Academy of Physical Education, Katowice, Poland ${ }^{2}$ The Academy of Business, Dąbrowa Górnicza, Poland

${ }^{3}$ Department of Kinesitherapy and Special Methods of Physiotherapy, The Jerzy Kukuczka Academy of Physical Education, Katowice, Poland

${ }^{4}$ School of Health Sciences, Silesian Medical University, Katowice, Poland

${ }^{5}$ Department of Physiotherapy, High Administration School, Bielsko-Biała, Poland

\begin{abstract}
Aim of the study: To determine the effect of a 4-week Nordic walking training on the physical fitness of women of the perimenopausal age and self-assessment of the quality of their health.

Material and methods: Eighty-four women between 48 and 58 years of age were included in the study. Half of the group (42) was assigned to the control group and the other half was assigned to the experimental group. In both groups studied, physical fitness was evaluated using a modified Fullerton's test and a quality of life self-assessment SF-36 (Short Form of Health Status Questionnaire). Similar tests were repeated 4 weeks later. In the experimental group, a Nordic walking training was conducted between the two tests. During 4 weeks, 10 training sessions were performed, each session was 60 minutes long, and there was an interval of 2 days between the sessions.

Results: A 4-week Nordic walking training resulted in a significant improvement $(p<0.001)$ of physical fitness as demonstrated by an increased strength and flexibility of the upper and lower part of the body and the ability to walk a longer distance during a 6-minute walking test. Women participating in the training also showed a significant improvement in health in terms of both physical health $(p<0.001)$ and mental health $(p<0.001)$.

Conclusions: A 4-week Nordic walking training has a positive effect on the physical fitness of the women in the perimenopausal age. Participation in training contributes also to a clearly higher self-assessment of the quality of health.
\end{abstract}

Key words: perimenopausal age, physical fitness, walking training, quality of health.

\section{Introduction}

Modern conveniences of developed civilization manifested as urban solutions, the omnipresence of means of transportation and the use of machines and computers reduce physical activities and limit the motor potential, and the activities which at one time were critical for the survival of an individual. Professional activity requires less and less physical activity. This is associated with the passive use of free time with a limited contact with nature. Sedentary lifestyle, high-calorie and a less than perfect diet and limited exercising are the basis for health regression and as a result create the conditions for the development of many diseases which are called civilization diseases for a reason. The perimenopausal period in women is a critical period in which bad effects of various habits associated with the lifestyle are superimposed on natural changes associated with the end of the fertility period [1-5]. Limited physical activity and nutritional mistakes are considered as some of the negative habits that disadvantageously contribute to the health of women in the menopausal period. In that period of life women reduce their physical activity by as much as $40 \%$ [1, 2]. Diet poor in vegetables and fruits but with an excess of animal fats, carbohydrates and salt is one of the cardiometabolic risk factors [6]. The need for physical activity for maintaining health of menopausal women is emphasized $[7,8]$. The problem is, however, the type of physical activity. A loss of physical attractiveness with a decrease in physical and mental fitness as a natural result of aging processes make it difficult to continue current forms of physical activity, and if a woman did not exercise before, she is not ready to start doing it during the perimenopausal period. In the contemporary world, fixated on physicality and youth, menopausal women tend to 
withdraw from exercises rather than maintain physical fitness. Fitness Centres promoted in the media are full of young and most often, physically attractive females, not mature women, for whom this type of facilities usually is associated with negative experiences.

Walking is the simplest, natural, and at the same time, the most frequent form of human exercise. Since we began walking on two legs, we do it every day while performing various daily activities. Of course, if walking is to positively impact our body and be comparable with the effects of athletic practice, it has to be performed on a regular basis and be intense enough to cause optimal for the age energy expenditure. This type of exercise should also be safe and, significantly in terms of health, enjoyable. This type of pro-health consideration almost immediately excludes the situations in which we hurry for work, come back home or nervously do shopping running from one store to another. Nordic walking is a special walking practice which has a positive physical and mental effect on human body. Walking with poles was conceived in 1920s by ski runners in Finland and served as a "dry run" before winter. This type of walking practice came back after 1997, crossed the borders of the Scandinavian countries and became popular practically in the entire Western and Central Europe [9]. The popularity of Nordic walking is caused by its simplicity and accessibility, almost everybody can practice it everywhere and in any season. This type of physical activity seems very attractive especially to people past their prime. No expenses and no special motor abilities in addition to walking are required to undertake Nordic walking.

Having in mind beneficial effects of walking, the goal of this report was to determine the effect of a 4-week Nordic walking practice on perimenopausal women's physical fitness and the effect of this type of activity on self-assessment of their health.

\section{Material and methods}

A group of 84 women of 48 to 58 years of age who live in the Silesia province were included in the study. Half of the group (42) was selected to be the control group and the other 42 women were in the experimen-

Tab. I. Demographic data of the participants, according to the group

\begin{tabular}{lccc}
\hline Features & $\begin{array}{c}\text { Nordic walking } \\
\text { group }\end{array}$ & $\begin{array}{c}\text { Control } \\
\text { group }\end{array}$ & $p$ \\
\hline Age (years) & $52.3 \pm 2.6$ & $51.9 \pm 3.0$ & $0.564^{\#}$ \\
\hline Weight $(\mathrm{kg})$ & $69.2 \pm 7.9$ & $69.3 \pm 8.5$ & $0.989^{\#}$ \\
\hline Height $(\mathrm{cm})$ & $162.1 \pm 3.6$ & $163.0 \pm 7.5$ & $0.171^{\ddagger}$ \\
\hline BMI $\left(\mathrm{cm} / \mathrm{kg}^{2}\right)$ & $26.4 \pm 3.1$ & $26.4 \pm 4.7$ & $0.802^{\ddagger}$ \\
${ }^{\#} p$ value for $t$ test for independent samples \\
${ }^{\ddagger} p$ value for $U$ Mann Whitney test & &
\end{tabular}

tal group. The inclusion criteria in the experimental group were: age (48-58 years), contraindications for health reasons to perform moderately intense exercises and intensive walking, consent to the participation in the studies. The control group was composed of women of similar ages who consented to participation in the study and were not willing to regularly practice walking for 4 weeks. The characteristics of women studied in both groups and intergroup comparisons are presented in Table I.

All procedures associated with the study were performed in accordance with the Helsinki Declaration of 1975 and modified in 1983. The women studied were informed of the objective of the study and its course and advised that they may refuse to participate in the studies without stating the reason. All participants consented to the processing of their personal data to the extent required for conducting the study in a manner that prevents their identification by other persons. Consent was obtained from the University Bioethics Committee for Scientific Studies which was included in Resolution No. 10/2013, dated 21 November 2013.

The modified Fullerton Functional Fitness Test [10] was performed twice - before Nordic walking training (initial examination) and immediately after its completion (final examination). This test was composed of 5 exercises which included the evaluation of strength endurance: of the upper (the Arm Curl) and lower part of the body (a $30 \mathrm{~s}$ Chair Stand), the evaluation of the flexibility of the upper (Back Scratch) and lower (Chair Sit-and Reach) part of the body and a 6-minute walk. In both strength tests, the number of properly performed trials (bending of the forearm and its supination for the upper part of the body and a full cycle from sitting down, getting up and sitting down again on the chair for the upper part [sic] of the body) for 30 seconds were taken into account. An indirect measure of flexibility was the distance between the tips of the middle fingers (upper body flexibility trial) and the tip of the middle finger and the toes of the foot of the dominant leg (lower body flexibility trial). In both flexibility trials, the measurements were taken with a rigid tailor measuring tape with the accuracy of $0.5 \mathrm{~cm}$. Touching with the finger tips of the hands (upper body part) and hand tips [sic] the toes (lower body part) was assumed to be a normal value ("0"). Any deficit was expressed as a negative number and the outcome better than normal was expressed in positive numbers. The last trial tested the greatest distance (in meters) walked along a $20 \times 4$ metre rectangle during a 6-minute walk.

The quality of life in terms of health of the individuals examined was assessed using a SF-36 (Short Form of Health Status Questionnaire) [11, 12]. This questionnaire is composed of 36 closed questions asking for information how the individual is doing in 8 aspects of health groups in two categories - physical 
and mental. Responses to each question are scored progressively on a scale from 0 to 100 . The greater the score, the higher assessment of one's own body in a particular aspect.

There were 10 sessions during a 4-week training programme. The sessions were separated by 2-day intervals. Each training session, which lasted 60 minutes, started with a 10-minute warm-up period. A warm-up involved a moderate walk while performing exercises intended to prepare specific parts of the body for exertion (e.g. raising arms, bending and twisting of the body, lifting of the knees). The main phase of the training lasted 40 minutes. Walking was carried out on a flat, wooded and hard area. The first training started with learning the Nordic walking technique. Initially, it was walking with poles loosely hanging along the body. After finding an appropriate individual rhythm of walking, subsequent elements of the use of the poles to push back against them were included. Each time during training, the participants walked a distance of approximately $5 \mathrm{~km}$. Walking was performed with variable speed and gait of variable length and intensity of use of the poles were applied. The final stage of the training was a 10-minute phase in which the speed of walking was reduced and stretching exercises were included during walking.

Statistical evaluation of the results included the calculation of basic data of descriptive statistics (arithmetic means and standard deviations). To determine whether the groups studied were homogenous, Student's t-test for independent samples and $U$ Mann Whitney's test for the variables with heterogeneous variances in the Levene's test were employed. Dependent variables were analysed using the one-way analysis of variance (ANOVA) for repeated measurements with the between factor as a group (Nordic walking vs. control) and within factor as a time of measurement (first vs. second). For all test analyses, $p \leq 0.05$ was adopted as a critical statistical significance threshold.

\section{Results}

A comparison of both groups (Table I) did not show any statistically significant differences in basic biometric data (age, body weight and height, BMI) between the women participating in the training programme and the women of the control group. Thus, a statement can be made that in this sense the groups were homogenous. This allows an exclusion of the effect of body weight and height, and excess of weight and obesity on the level of physical functions and self-assessment of the quality of health of the women studied.

The post hoc analysis of the variables included in the Fullerton test demonstrated that in the case of the upper body strength, lower body strength and lower body flexibility statistically significant intergroup differences were present in measurements 1 and 2 (each, $p<0.001)$. However, the intergroup differences were significantly lower before the training (0.82 for upper body strength; 2.29 for lower body strength; -2.04 for lower body flexibility) than after training (3.29 for upper body strength; 4.56 for lower body strength; -3.22 for lower body flexibility). In the control group, differences were not demonstrated between measurements 1 and $2(p>0.482)$, but in turn in the Nordic walking group a significant increase in the value of upper body strength and lower body strength and lower body flexibility (each, $p<0.001$ ) after training was recorded. In terms of the upper body flexibility and the 6-minute walk, variable significant intergroup differences were not demonstrated in measurement 1 (each, $p>0.05$ ), as well as differences between measurements 1 and 2 in the control group (each, $p>0.922$ ). However, significant intergroup differences occurred in measurement 2 (each, $p<0.001$ ) and in the Nordic walking group between measurements 1 and 2 (each, $p<0.001$ ). The mean values for all results of the Fullerton test in the individual groups, as well as results of the main effects and interaction (group $x$ measure) of the ANOVA test are presented in Table II.

Tab. II. The results of Fullerton Fitness Test in the Nordic walking and control groups

\begin{tabular}{|c|c|c|c|c|c|c|c|}
\hline \multirow{3}{*}{$\begin{array}{l}\text { Dependent } \\
\text { variables }\end{array}$} & \multicolumn{2}{|c|}{ Nordic walking group } & \multicolumn{2}{|c|}{ Control group } & \multicolumn{3}{|c|}{$p$ value from ANOVA } \\
\hline & \multirow{2}{*}{$\begin{array}{c}\text { First } \\
\text { measurement }\end{array}$} & \multirow{2}{*}{$\begin{array}{c}\text { Second } \\
\text { measurement }\end{array}$} & \multirow{2}{*}{$\begin{array}{c}\text { First } \\
\text { measurement }\end{array}$} & \multirow{2}{*}{$\begin{array}{c}\text { Second } \\
\text { measurement }\end{array}$} & \multicolumn{2}{|c|}{ Main effect } & \multirow[t]{2}{*}{ Interaction } \\
\hline & & & & & Group & Measurement & \\
\hline $\begin{array}{l}\text { Upper body } \\
\text { strength }\end{array}$ & $15.7 \pm 3.2$ & $17.9 \pm 3.8$ & $14.9 \pm 2.9$ & $14.7 \pm 3.0$ & ** & $* * *$ & $* * *$ \\
\hline $\begin{array}{l}\text { Lower body } \\
\text { strength }\end{array}$ & $15.8 \pm 2.7$ & $18.3 \pm 2.8$ & $13.6 \pm 3.1$ & $13.7 \pm 3.1$ & $* * *$ & $* * *$ & $* * *$ \\
\hline $\begin{array}{l}\text { Upper body } \\
\text { flexibility }\end{array}$ & $-5.1 \pm 6.8$ & $-1.4 \pm 5.3$ & $-4.1 \pm 5.3$ & $-4.0 \pm 5.1$ & 0.499 & $* * *$ & $* * *$ \\
\hline $\begin{array}{l}\text { Lower body } \\
\text { flexibility }\end{array}$ & $0.13 \pm 6.9$ & $2.0 \pm 6.5$ & $-1.9 \pm 6.9$ & $-1.2 \pm 8.1$ & 0.887 & $* * *$ & 0.089 \\
\hline $\begin{array}{l}\text { The 6-minute } \\
\text { walk }\end{array}$ & $524.8 \pm 65.4$ & $568.3 \pm 56.6$ & $527.8 \pm 64.1$ & $525.7 \pm 63.9$ & 0.144 & $* * *$ & $* * *$ \\
\hline
\end{tabular}


The post hoc analysis of the variables from the SF-36 questionnaire indicated significant intergroup differences in measurements 1 and 2 for the Emotional well-being variable $(p<0.001$ and $p<0.01$, respectively). The analysis of the mean values revealed that in comparison to the control group, in the Nordic walking group the values recorded were lower by approximately 5.91 points for measurement 1 . On the other hand, measurement 2 in the Nordic walking group recorded higher values by approximately 4.13 points. The intragroup differences were only observed in the Nordic walking group $(p<0.001)$, where in measurement 2 the recorded increase was of approximately 10 points. The control group obtained identical results in measurements 1 and $2(p=1.00)$. For Role limitations due to emotional problems and Energy/fatigue variables significant intergroup differences were indicated in measurement 1 (each, $p<0.001$ ), and higher values were recorded in the control group. Measurement 2 did not record significant intergroup differences (each, $p>0.18)$. On the other hand, the intragroup difference (measurement 1 vs. 2) for these variables was noted only in the Nordic walking group (each, $p<0.001$ ), where measurement 2 recorded a significant increase in the value of both variables. For the Physical function- ing variable, significant intragroup differences were recorded $(p<0.001)$ between measurements 1 and 2 in the Nordic walking group, as well as intergroup differences in measurement $2(p<0.001)$. For the General health variable only the difference between measurement 1 and 2 in the Nordic walking group was recorded $(p<0.05)$. The mean values for all individual variables that are included in the SF-36 questionnaire in the individual groups, as well as the results of main effects and interaction (group $x$ measure) of the ANOVA test are included in Table III that also demonstrates no differences for the variables: Role limitations due to physical health, Pain and Social functioning.

For the results of variables calculated based on the SF-36 questionnaire, thus 2 components of health physical and mental post hoc analysis revealed statistically significant intergroup differences ( $p<0.01$ for physical health; $p<0.001$ for mental health component) in measurement 1 . For the physical health component and mental health component lower values were recorded in the Nordic walking group (4.2 and 8.36 points, respectively). In the second assessment, significant intergroup differences were not present (each, $p>0.90$ ). In the Nordic walking group statistically significant intragroup differences were recorded between measurements 1

Tab. III. The results of physical and mental components of health (SF-36) in the Nordic walking and control groups

\begin{tabular}{|c|c|c|c|c|c|c|c|}
\hline \multirow{3}{*}{$\begin{array}{l}\text { Dependent } \\
\text { variables }\end{array}$} & \multicolumn{2}{|c|}{ Nordic walking group } & \multicolumn{2}{|c|}{ Control group } & \multicolumn{3}{|c|}{$p$ value from ANOVA } \\
\hline & \multirow{2}{*}{$\begin{array}{c}\text { First } \\
\text { measurement }\end{array}$} & \multirow{2}{*}{$\begin{array}{c}\text { Second } \\
\text { measurement }\end{array}$} & \multirow{2}{*}{$\begin{array}{c}\text { First } \\
\text { measurement }\end{array}$} & \multirow{2}{*}{$\begin{array}{c}\text { Second } \\
\text { measurement }\end{array}$} & \multicolumn{2}{|c|}{ Main effect } & \multirow[t]{2}{*}{ Interaction } \\
\hline & & & & & Group & Measurement & \\
\hline $\begin{array}{l}\text { Physical func- } \\
\text { tioning }\end{array}$ & $80.2 \pm 13.2$ & $85.9 \pm 11.5$ & $81.4 \pm 15.7$ & $81.3 \pm 15.7$ & 0.572 & $* * *$ & $* * *$ \\
\hline $\begin{array}{l}\text { Role limita- } \\
\text { tions due } \\
\text { to physical } \\
\text { health }\end{array}$ & $68.1 \pm 40.2$ & $72.1 \pm 36.1$ & $75.6 \pm 38.1$ & $77.4 \pm 38.6$ & 0.433 & 0.133 & 0.554 \\
\hline Pain & $61.2 \pm 22.5$ & $64.5 \pm 21.9$ & $63.3 \pm 19.0$ & $62.3 \pm 17.5$ & 0.937 & 0.648 & 0.196 \\
\hline $\begin{array}{l}\text { General } \\
\text { health }\end{array}$ & $48.4 \pm 17.7$ & $52.6 \pm 18.4$ & $49.7 \pm 18.6$ & $51.6 \pm 20.6$ & 0.967 & ** & 0.231 \\
\hline $\begin{array}{l}\text { Physical } \\
\text { health com- } \\
\text { ponent }\end{array}$ & $64.5 \pm 20.9$ & $68.8 \pm 19.7$ & $68.7 \pm 16.2$ & $68.2 \pm 16.5$ & 0.648 & * & ** \\
\hline $\begin{array}{l}\text { Role limita- } \\
\text { tions due to } \\
\text { emotional } \\
\text { problems }\end{array}$ & $63.6 \pm 43.3$ & $77.7 \pm 37.6$ & $82.5 \pm 33.9$ & $84.1 \pm 33.1$ & 0.102 & $\star *$ & * \\
\hline $\begin{array}{l}\text { Energy/ } \\
\text { fatigue }\end{array}$ & $48.4 \pm 23.2$ & $59.3 \pm 23.3$ & $56.8 \pm 14.3$ & $55.6 \pm 15.1$ & 0.558 & $* * *$ & $* * *$ \\
\hline $\begin{array}{l}\text { Emotional } \\
\text { well-being }\end{array}$ & $55.1 \pm 24.9$ & $65.2 \pm 20.1$ & $61.0 \pm 14.6$ & $61.1 \pm 15.7$ & 0.828 & $* * *$ & $* * *$ \\
\hline $\begin{array}{l}\text { Social func- } \\
\text { tioning }\end{array}$ & $71.4 \pm 20.5$ & $72.4 \pm 19.1$ & $73.3 \pm 17.4$ & $71.2 \pm 17.1$ & 0.937 & 0.648 & 0.196 \\
\hline $\begin{array}{l}\text { Mental health } \\
\text { component }\end{array}$ & $59.6 \pm 25.2$ & $68.6 \pm 23.1$ & $68.0 \pm 15.3$ & $67.7 \pm 14.4$ & 0.385 & $* * *$ & $* * *$ \\
\hline
\end{tabular}


and 2 in both components of the self-assessment of the health $(p<0.01$ for physical health component; $p<0.001$ for mental health component). Table III contains the average values for these variables.

\section{Discussion}

Because of a significantly longer life expectancy, changes in the life style due to technical progress and unfavourable demographic trends, pro-health behaviours of middle aged and elderly adults become a challenge for the societies of highly developed countries. A physically active life style is inseparable from these behaviours. In this light, physical activity of Polish adults raises concerns. According to the studies performed by the East-West Health Gap in Finland, Spain, Germany, Poland and Russia, adult Poles were in the last place in terms of physical activity [13]. Physical fitness, in addition to such socioeconomic factors as education, marital status and income, along with proper diet, constitutes one of the basic factors for successful aging [14]. It is important, from the point of view of prohealth activities, that physical fitness can be modified. Broadly understood physical activity is the basic factor that contributes to fitness. For optimal health effects of physical activity it is important to select a proper form of activity, especially in the case of middle-aged women in whom negative effects of menopause add to degenerative aging mechanisms $[15,16]$. It seems that intense walking with poles is a proper form of physical activity. Popularity of Nordic walking continues to grow, and in Finland, which is where this activity was invented, 500 thousand people, i.e. 15\% of the entire population, practice it, and one in two Fins have contact with it at least once in a lifetime $[9,17]$.

Walking with poles, based on natural motor abilities, can provide a "dose" of physical activity required for health. There is a certain misunderstanding with regard to the use of poles during walking. A common belief is that they are supposed to partly take the load off the lower limbs, and therefore individuals with a diminished function of the lower limbs are predisposed to Nordic walking. Nothing can be further from the truth because the studies demonstrated that knees are not significantly relieved while walking with poles [18]. Their role is to uniformly spread the load over the entire body, or, in other words, engage more the trunk and upper limbs during walking. Of course the use of poles increases the stability of the body during walking. Thus it protects, to a certain degree, against falls, which is important for people who due to past trauma after a fall, are afraid of walking.

The results of the studies demonstrated that a fourweek Nordic walking training had a significant impact on physical fitness of women 48-58 years of age. A significant increase in the distance covered during a 6-minute walk is not surprising, because it is a natural consequence of systematically practiced intense walk. An increase in strength of the lower limbs can be similarly explained. Because intense arm work is essential to walking with poles, an increase in the strength of the upper body part, manifested as an improvement in the Arm Curl trial in the final examination, should be considered an immediate outcome of the training. On the other hand, improved flexibility is probably associated with a type of training associated with exercises performed during the initial part of each session (raising arms, bending and twisting the body, raising knees) which contained elements stretching longitudinal and oblique musculofascial bands of the upper and lower parts of the body. The final part of each training session consisted of moderate walking with stretching exercises. Beneficial effects of this type of physical activity in women are not an exception. Beneficial effects of this type of physical activity in women were demonstrated earlier. Rodgers et al. [19] demonstrated that a brisk 30-minute walk with poles increases oxygen consumption on average by $11 \%$, increases heart rate by $8 \%$ and energy expenditure by $18 \%$ compared with brisk walking. Hagner et al. [20] used a 12-week Nordic walking training in 168 women divided into 3 observational groups depending on menopause (premenopausal, perimenopausal and postmenopausal groups). Triglyceride levels and BMI were analysed. The overall level of triglycerides was reduced, so was the LDL level and the HDL level was increased, which unambiguously shows that this type of activity has a beneficial effect on the prophylaxis of cardiovascular diseases. Body mass index also significantly decreased. It is noteworthy that no intergroup differences were noted, which means that equally beneficial effects were observed in still menstruating women, in menopausal and postmenopausal women. In other studies, a significant body weight reduction and a decrease in arterial blood pressure in 23 obese women who participated in a 12-week long Nordic walking training programme [21] was noted. Taking into account these results, Nordic walking training can be recommended to the women who are instructed to lose weight, improve general physical fitness and prevent circulatory system diseases by exercising. Besides, the march training with poles is used in rehabilitation of those with the cardiovascular diseases and it is also recommended to patients that are treated for the cardiosurgical conditions [22].

According to a contemporary, holistic definition of health we do not concentrate on illness but on health and its model with three aspects: physical, mental and social. The holistic health paradigm emphasises the role of individual in attaining health [23]. In light of this, the assessment by the individual of the effectiveness of pro-health actions is of particular importance. In our studies, the subjective assessment of the quality of life 
(SF-36) in women participating in training improved significantly along with an objective improvement of physical fitness. After 4 weeks of Nordic walking training, self-assessment of both health components (physical health component and mental health component) improved. After a 4-week Nordic walking training, the evaluation of the physical health component increased by approximately 4.3 points, and evaluation of the mental health component increased by approximately 9 points. Among the women from the control group that experienced habitual physical activity typical of them, the self-assessment of both health components has practically not changed (about -0.5 points for physical health component and about -0.3 points for mental health component). It is noteworthy that a significantly greater effect was observed for the mental health component. Such a significant improvement in physical fitness of women participating in the study would suggest a greater effect on the physical health component. It may be that the reason for this pattern of the results can be found in the social role of women in the family and professional life. The inability to satisfy the associated needs has a more profound emotional impact. This may be the reason why improvement in physical fitness so significantly affects the mental health component. However, at this stage these are only speculations. It is difficult to compare the results of these studies to the results of other authors. Although quality of life assessment using an SF-36 questionnaire was already performed in other studies evaluating the impact of Nordic walking training but it was not used for a population of potentially healthy women of the perimenopausal age. A significant improvement in health self-assessment as a result of rehabilitation with Nordic walking was demonstrated in patients with peripheral artery disease [24], chronic obstructive pulmonary disease [25] and chronic neck pain [26].

Nordic walking as a physical activity recommended to individuals especially of somewhat advanced age is associated with its safety. A long-term observation lasting a total of 29,160 hours of Nordic walking in 101 healthy women and 36 healthy men showed 0.926 injury per $1,000 \mathrm{~h}$ of walking [27]. By comparison, in basketball and squash, 14 injuries per 1,000 h of sport are recorded. The only injury specific to Nordic walking can be a thumb injury. The most frequently encountered injury was an injury to the lateral ligament of the thumb which occurred with a frequency of $0.206 / 1,000 \mathrm{~h}$ of walking. In general, upper limbs are at a greater risk of trauma (0.549/1,000 h) than lower limbs (0.344/1,000 h). However, more serious injuries such as shoulder displacement $(0.069 / 1,000 \mathrm{~h})$, fracture of the distal part of the radial bone and sprain of the ankle $(0.034 / 1,000 \mathrm{~h})$ occur very infrequently. Compared with other forms of physical activities, these data show that the incidence of injuries due to Nordic walking is insignificant. It is noteworthy that all individuals who were injured, returned to their earlier physical activity within 4 weeks [27]. Because of these data, Nordic walking, like few other physical activities can be used by middle aged and elderly individuals who earlier did not exercise a great deal or did not exercise at all and are prone to injuries if they start exercising.

Of course, these studies do not exhaust all possibilities of increasing physical fitness by Nordic walking of women of perimenopausal age. Studies on a broader population, with different levels of physical activity should be performed, including monitoring of longterm effects. However, the results of these studies demonstrate that Nordic walking can be recommended to middle-aged women as an accessible, cheap and safe form of motor prophylaxis.

\section{Conclusions}

A 4-week Nordic walking training caused a significant improvement of physical fitness of women 48-58 years of age. Increased physical fitness of women participating in the Nordic walking significantly improved subjective assessment of the quality of health. The results obtained in these studies lead to the conclusion that walking with poles as in Nordic walking should be promoted as a simple, cheap and safe, and above all effective form of exercise which can offset the negative impact of the sedentary lifestyle in middle-aged women.

\section{Disclosure}

Authors report no conflicts of interest.

\section{References}

1. Elavsky S. Physical activity, menopause, and quality of life: the role of affect and self-worth time. Menopause 2009; 16: 265-271.

2. Evenson K, Wilcox S, Pettinger $M$, et al. Vigorous leseure activity through women's adult life. Am J Epidemiol 2002; 156: 945-953.

3. Keller C, Larkey L, Distefano J, et al. Perimenopausal obesity. J Womens Health (Larchmt) 2010; 19: 987-996.

4. Levejoy JC. Weight gain in women at midlife: the influence of menopause. Obesity Manage 2009; 5: 52-56.

5. Rizk DE, Bener A, Ezimokhai $M$, et al. The age and symptomatology of natural menopause among United Arab Emirates women. Maturitas 1998; 29: 197-202.

6. Ventura D de A, Fonseca V de M, Ramos EG, et al. Association between quality of the diet and cardiometabolic risk factors in postmenopausal women. Nutr J 2014; 13: 121.

7. Dąbrowska J, Naworska B, Dąbrowska-Galas M, Skrzypulec-Plinta V. Rola wysiłku fizycznego w okresie menopauzy. Prz Menopauzalny 2012; 11: 445-448.

8. Piotrowska S, Majchrzycki M. Ćwiczenia fizyczne u kobiet po menopauzie. Prz Menopauzalny 2013; 12: 347-351.

9. Kocur P, Wilk M. Nordic Walking - a new form of exercise in rehabilitation. Medical Rehabilitation 2006; 10: 1-8.

10. Różańska-Kirschke A, Kocur P, Wilk M, Dylewicz P. The Fullerton Fitness Test as an index in the elderly. Rehabilitacja Medyczna 2006; 10: 15-19. 
11. Knapik A, Saulicz E, Kuszewski M, Plinta R. An analysis of relations between a self-assessment of health and active life-style. Medicina Sportiva 2009; 13: 17-21.

12. Ware JE, Sherbourne CD. The MOS 36-item Short Form Health Survey (SF-36). Medical Care 1992; 30: 473-483.

13. Rutkowska E. Aktywność fizyczna w medycynie holistycznej. Wychowanie Fizyczne i Sport 2004; 48: 175-180.

14. Knapik A, Saulicz E, Plinta R, Kuszewski M. Aktywność fizyczna a zdrowie kobiet w starszym wieku. J Orthop Trauma Surg Relat Res 2011 6: 27-33.

15. McArthur D, Dumas A, Woodend K, et al. Factors influencing adherence to regular exercise in middle-aged women: qualitative study to inform clinical practice. BMC Women's Health 2014; 14: 49.

16. Najmabadi KM. Exercise prescription for Iranian midlife women. Int J Gen Med 2010; 3: 365-369.

17. Turk Z, Vidensek S, Micetic-Turk D. Nordic walking: a new form of physical activity in the elderly. Acta Medicinae Croatica 2007; 61 (Suppl 1): 33-36.

18. Hansen L, Henriksen M, Larsen P, Alkjaer T. Nordic Walking does not reduce the loading of the knee joint. Scand J Med Sci Sports 2008; 18 436-441.

19. Rodgers CD, Van Heest JL, Schachter CL. Energy expenditure during submaximal walking with Exerstriders. Med Sci Sports Exerc 1995; 27: 607-611.
20. Hagner W, Hagner-Derengowska M, Wiacek M, Zubrzycki IZ. Changes in level of VO2max, blood lipids, and waist circumference in the response to moderate endurance training as a function of ovarian aging. Menopause 2009; 16: 1009-1013.

21. Figard-Fabre H, Fabre N, Leonardi A, Schena F. Efficacy of Nordic walking in obesity management. Int J Sports Med 2011; 32: 407-414.

22. Kocur P, Krzywicka-Michałowska M, Wilk M, Dylewicz P. The importance and effectiveness of walking training in cardiac rehabilitation with special regard to patients after cardiac burger. Kardiochir Torakochir Pol 2012; 9: 481-485.

23. Dolińska-Zygmunt G. Teoretyczne podstawy refleksji o zdrowiu. In: Podstawy psychologii zdrowia. Dolińska-Zygmunt $\mathrm{G}$ (red.). Wydawnictwo Uniwersytetu Wrocławskiego, Wrocław 2001; 11-18.

24. Collins EG, Langbein WE, Orebaugh C, et al. Cardiovascular training effect associated with polestriding exercise in patients with peripherial arterial disease. J Cardiovasc Nurs 2005; 20: 177-185.

25. Breyer MK, Breyer-Kohansal R, Funk GC, et al. Nordic walking improves daily physical activities in COPD: a randomised controlled trial. Respir Res 2010; 11: 2-9.

26. Henkel J, Bak P, Otto R, Smolenski UC. Effect of selected prevention concepts on functional health of persons with nonspecific chronic recurrent neck pain. Manual Med 2008; 47: 57-66.

27. Knobloch K, Vogt PM. Nordic pole walking injuries - nordic walking thumb as novel injury entity. Sportverletzungen und Sportschäden 2006; 20: 137-142. 